Published online: April 25, 2009

\title{
Successful Treatment in a Case of Massive Hepatocellular Carcinoma with Paraneoplastic Syndrome
}

\author{
Atsunori Tsuchiya ${ }^{a}$ Tomoyuki Kubota ${ }^{a}$ \\ Kazuyoshi Takizawa ${ }^{a}$ Kazuki Yamada ${ }^{a}$ Toshifumi Wakai ${ }^{b}$ \\ Yasunobu Matsudad $^{d}$ Terasu Honma $^{e}$ Masashi Watanabe ${ }^{e}$ \\ Yoshio Shirai $^{\mathrm{b}}$ Hiroki Maruyamac Minoru Nomoto ${ }^{\mathrm{a}}$ \\ Yutaka Aoyagi ${ }^{\mathrm{a}}$ \\ ${ }^{\mathrm{a} D i v i s i o n}$ of Gastroenterology and Hepatology, ${ }^{\mathrm{b}}$ Division of Digestive and General \\ Surgery, and 'Department of Clinical Nephroscience, Niigata University Graduate \\ School of Medical and Dental Science, and dDepartment of Medical Technology, \\ Niigata University Graduate School of Health Sciences, Niigata; eNiigata \\ Preferctural Shibata Hospital, Shibata, Japan
}

\section{Key Words}

Hepatocellular carcinoma - Paraneoplastic syndrome - Erythrocytosis · Hyperlipidemia

\begin{abstract}
Paraneoplastic syndromes of hepatocellular carcinoma (HCC) are not uncommon. However, the prognosis is poor and follow-up and improvement of paraneoplastic syndromes with treatment have been reported rarely. We report a successful case in an aged man of a massive HCC with paraneoplastic syndrome, treated by combined intraarterial chemotherapy and hepatic resection. Paraneoplastic syndrome (erythrocytosis and hyperlipidemia) was monitored throughout the treatment and erythropoietin (EPO) mRNA also was analyzed in the resected liver. The hemoglobin level and serum levels of EPO and total cholesterol (T-cho) decreased dramatically with treatment, along with a decrease in serum levels of a-fetoprotein and protein induced by vitamin vitamin $\mathrm{K}$ absence II (PIVKA-II). Semiquantitative reverse transcription polymerase chain reaction (RT-PCR) revealed that the residual cancer expressed EPO RNA but the nontumor tissue did not. This was a rare case of paraneoplastic syndrome of HCC that was treated successfully. This case indicates that paraneoplastic syndrome reflected tumor progression and that serum levels of both EPO and T-cho might be used as tumor markers.
\end{abstract}




\section{Introduction}

Hepatocellular carcinoma (HCC) sometimes manifests with a variety of paraneoplastic syndrome, such as hypoglycemia $[1,2]$, erythrocytosis $[1,3]$, hypercalcemia $[1,4,5]$, hypercholesterolemia [1], and thrombocytopenia [6]. Although the reported frequency of paraneoplastic syndrome varies from 1 to $40 \%$, most HCC patients with paraneoplastic syndrome have massive tumors and increased levels of $\alpha$-fetoprotein (AFP) $[1-3,6]$. The symptoms of some paraneoplastic syndromes, such as hypoglycemia, may be detected early and must be treated as soon as possible. However other paraneoplastic syndromes, such as erythrocytosis and hyperlipidemia, are silent and often detected too late, unless recognized by chance. Thus, treatment of HCC patients with paraneoplastic syndrome has proved difficult, despite therapies such as surgery and chemotherapy, including transarterial chemoembolization $[2,3]$. Furthermore, these therapies were sometimes restricted by complications and liver function. These cases with delayed detection died without sufficient treatment. Here, we report a successful case of combined therapy, including intraarterial neoadjuvant chemotherapy using CDDP and surgery, for an aged man with a massive HCC with erythrocytosis and hypercholesterolemia. The serum levels of erythropoietin (EPO) and total cholesterol (T-cho) were monitored throughout the treatment and EPO RNA also was analyzed in the tumor and nontumor tissue.

\section{Case Report}

An 81-year-old man with angina pectoris was admitted to our hospital on May 20, 2007 for removal of a massive liver tumor on the right lobe. Laboratory data showed erythrocytosis (red blood count $563 \times 10^{4} / \mu \mathrm{l}$, hemoglobin level $16.4 \mathrm{~g} / \mathrm{dl}$, hematocrit $51.6 \%$, and serum EPO $93.9 \mathrm{mU} / \mathrm{ml}$; normal range $12.5-34.5 \mathrm{mU} / \mathrm{ml}$ ) and hypercholesterolemia (T-cho $363 \mathrm{mg} / \mathrm{dl}$; he had been taking $10 \mathrm{mg}$ atrovastatin calcium orally daily). Tests for hepatitis B and C virus markers were all negative. He rarely drank alcohol. Liver function test disclosed the following values: total bilirubin (TB) $0.6 \mathrm{mg} / \mathrm{dl}$, aspartate aminotransferase $83 \mathrm{IU} / \mathrm{l}$, alanine aminotransferase $37 \mathrm{IU} / \mathrm{l}$, alkaline phosphatase $694 \mathrm{IU} / \mathrm{l}$, serum albumin $3.4 \mathrm{~g} / \mathrm{dl}$, and PT-INR 1.08. There was a marked elevation of tumor markers such as AFP $(900,100 \mathrm{ng} / \mathrm{ml})$ and PIVKA-II (10,700 mAU/l). Ultrasonography and computed tomography showed a large mass measuring $12 \mathrm{~cm}$ in diameter in the right lobe of the liver (fig. 1a). The clinical diagnosis of this large mass was HCC. It was necessary to implant a coronary stent to treat severe angina pectoris, and anti-platelet therapy was carried out for at least one month to prevent restenosis of the stent. Therefore, prior to hepatic resection, transcatheter intraarterial injection of CDDP (I-A call ${ }^{\circledR}$ : total $80 \mathrm{mg}$ ) mainly to the right lobe was performed on May 30, 2007. After the CDDP injection, tumor size (fig. 1b) and serum AFP level (ig. 2 a) decreased gradually. About three weeks after CDDP administration, along with the reduction of tumor size, hemoglobin level, serum EPO and T-cho also decreased, to $13.8 \mathrm{~g} / \mathrm{dl}, 11.1 \mathrm{mU} / \mathrm{ml}$ and $247 \mathrm{mg} / \mathrm{dl}$, respectively (fig. $2 \mathrm{~b}$ ). A right lobectomy was performed on July 31 after implantation of the coronary stent. The tumor was almost necrotic and minimum residual cancer was detected. This residual cancer was diagnosed as poorly to moderately differentiated HCC. Nonalcoholic steatohepatitis (NASH) with mild fibrosis also was diagnosed in the resected liver (fig. 3a, b). EPO expression was detectable by semiquantitative reverse transcription polymerase chain reaction (RT-PCR) in the residual tumor, but no expression was detected in the resected liver without cancer (fig. 3c). Additional intraarterial CDDP administration was performed 3, 6 and 9 months after surgery. Up to now, recurrence of HCC and elevation of tumor markers have not been detected.

\section{Discussion}

Reports of HCC patients with paraneoplastic syndrome are not uncommon [1-6]. Four paraneoplastic syndromes have been reported in a single patient [1]. However, their prognosis has been poor except for rare successful cases treated with surgery and transarterial chemoembolization $[2,3]$. Except for these rare cases, patients have died 
soon after tumor detection without sufficient therapy [1, 3, 4-6]. In this report, an aged HCC patient with paraneoplastic syndrome and angina pectoris was treated successfully with combined neoadjuvant CDDP administration and surgery. This report is a rare case of HCC with paraneoplastic syndrome that was treated successfully; the markers of paraneoplastic syndromes could be monitored throughout the treatment.

In this case, elevation of the serum level of EPO and cholesterol was detected. Matsuyama et al. [3] reported the detection of EPO in tumor cells by immunohistochemistry. In this study, expression of EPO was detected in the residual tumor but not in nontumorous liver tissue. This suggests that the tumor cells produced EPO. On the other hand, the mechanism whereby hyperlipidemia occurs cannot be explained clearly. Hirayama et al. [7] analyzed hepatoma-bearing rats with hyperlipidema and concluded that hypercholesterolemia was caused by increased cholesterol efflux from tumors as a result of activation of the liver $\mathrm{X}$ receptor $\alpha$ and overexpression of the sterol regulatory element-binding protein processing system contributing to activation of liver $\mathrm{X}$ receptor $\alpha$ by maintaining high oxysterol levels in tissue. These reports and associated data suggest that these markers may be used as tumor markers and that early detection of paraneoplastic syndrome can improve the prognosis of the patients. In fact, in this case, the hemoglobin level and serum levels of EPO and T-cho did indeed reflect tumor progression and were used as tumor markers.

CDDP often has been used for the treatment of HCC. In this case CDDP was very effective. This may be a rare case, however the dramatic effect of CDDP suggests that this may become an option for similar high-risk patients.

Recently, because patients at high risk for HCC have been followed up closely, small HCCs have been detected at an early date. Nevertheless, patients are often found with large HCCs. This patient was diagnosed with NASH by his resected liver and this suggests that patients with NASH also must be followed up carefully. This case also suggests that patients with paraneoplastic syndrome such as erythrocytosis or hyperlipidemia must be suspected of cancer, such as HCC. In these cases of early detection, the lives of some patients can be prolonged. 
Fig. 1. Computed tomography before and after neoadjvant chemotherapy. a Before chemotherapy, a massive HCC measuring $12 \mathrm{~cm}$ in diameter occupied the right lobe of the liver. b At day 30 after neoadjuvant chemotherapy, the size of the tumor was reduced to $7 \mathrm{~cm}$ in diameter.
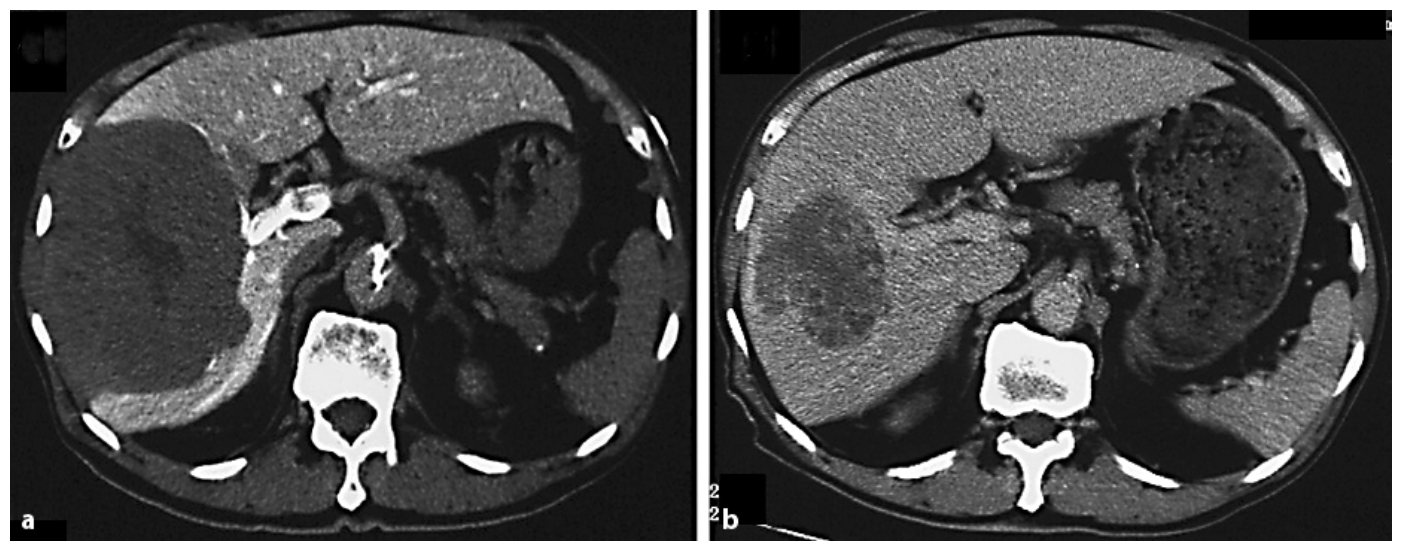

Fig. 2. Clinical course of the patient. a Tumor markers (AFP, PIVKA-II) decreased after neoadjuvant chemotherapy. These two markers fell to within the normal range after surgery. $\mathbf{b}$ The levels of serum T-cho and EPO also decreased after neoadjuvant chemotherapy. These levels fell to within the normal range before surgery.
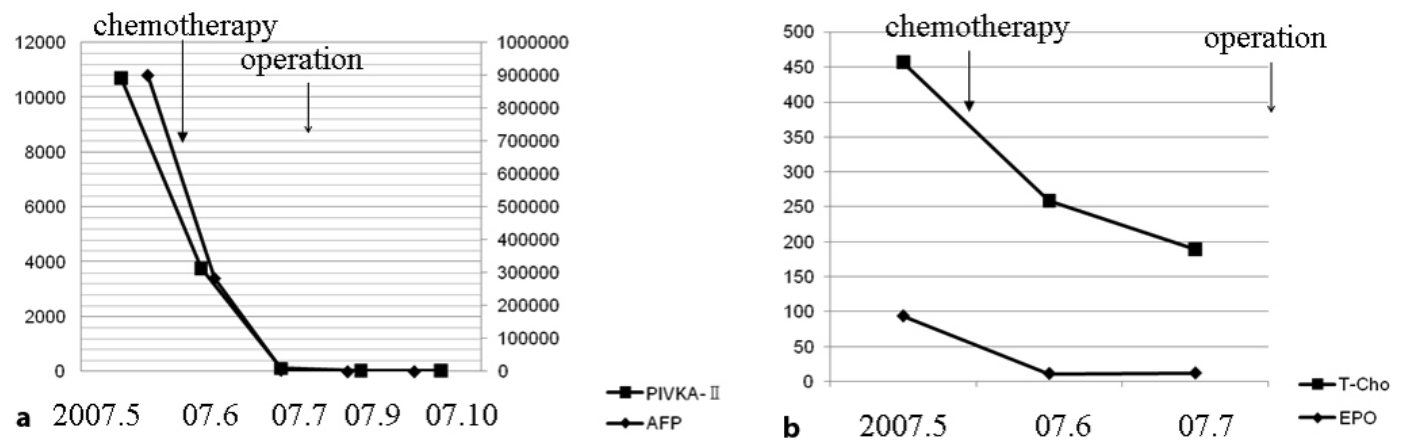


\begin{tabular}{r|l|l|l} 
Case Reports $/ \mathrm{h}$ & $\begin{array}{l}\text { Case Rep Gastroenterol 2009;3:105-110 } \\
\text { D0I: 10.1159/000213480 }\end{array}$ & Published online: April 25, 2009 & $\begin{array}{l}\text { O 2009 S. Karger AG, Basel } \\
\text { ISSN 1662-0631 } \\
\text { www.karger.com/crg }\end{array}$ \\
\hline
\end{tabular}

Fig. 3. Hematoxylin-eosin (HE) staining and RT-PCR analysis of the resected liver. a HE staining of the resected liver revealed that this patient suffered from NASH. Fatty change with chronic inflammation can be seen. Mallory's body also was detected (arrow, original magnification $\times 400$ ). $\mathbf{b}$ The residual liver tumor was moderately to poorly differentiated HCC. Many lymphocytes infiltrated the tumor.

c Semiquantiative RT-PCR revealed that the residual cancer expressed RNA for EPO but the non-umor area did not. Glyceraldehyde-3-phosphate dehydrogenase $(\mathrm{G} 3 \mathrm{PDH})$ was used as an internal control. $\mathrm{T}=$ Tumor, $\mathrm{N}$ = nontumor.
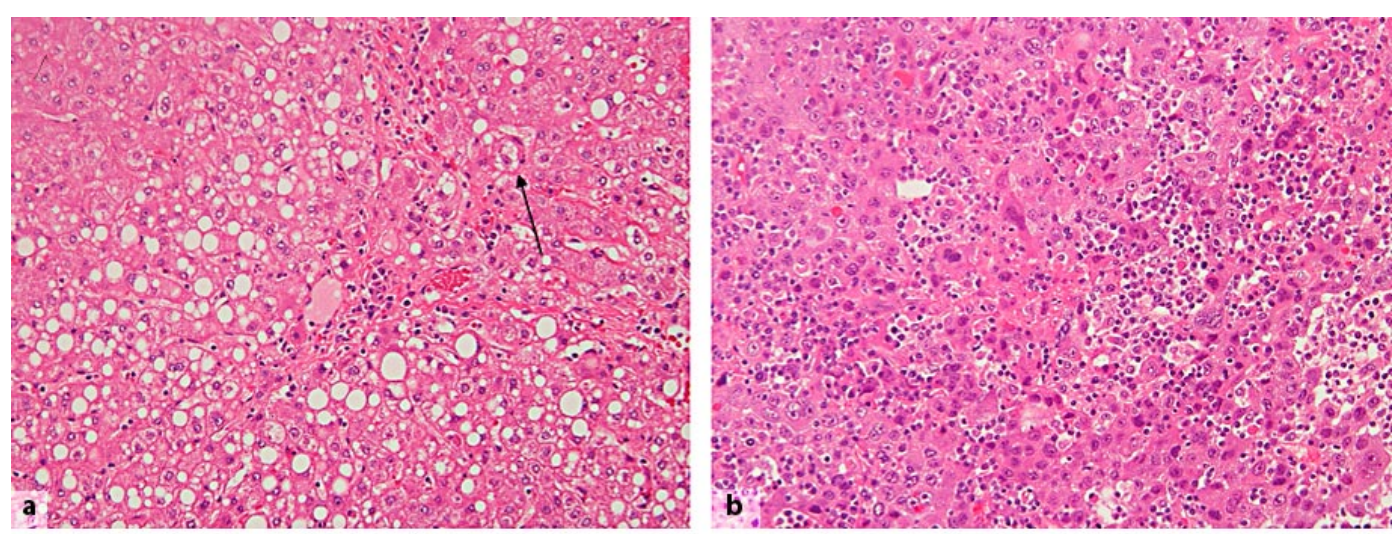
T N
Epo
c G3PDH 


\section{References}

- Chu CW, Hwang SJ, Luo JC, Tsay SH, Li CP, Chang FY, Lee SD, Lui WY, Chiang $\mathrm{JH}$ : Manifestations of hypercholesterolaemia, hypoglycaemia, erythrocytosis and hypercalcaemia in patients with hepatocellular carcinoma: report of two cases. J Gastroenterol Hepatol 1999;14:807-810.

-2 Kitazawa T, Nakamura S, Sano Y, Hishiki S, Sakaguchi S, Maeda M, Muro H, Kurahashi H, Yamamoto K: Successful resection of giant hepatocellular carcinoma with hypoglycemic attack. Nippon Geka Gakkai Zasshi 1984;85:15911596.

-3 Matsuyama M, Yamazaki O, Horii K, Higaki I, Kawai S, Mikami S, Higashino M, Oka H, Nakai T, Inoue T: Erythrocytosis caused by an erythropoietin-producing hepatocellular carcinoma. J Surg Oncol 2000;75:197-202.

4 Tudela P, Soldevila B, Modol JM, Domenech E: Hypercalcemic encephalopathy in a patient with hepatocellular carcinoma. Dig Dis Sci 2007;52:3296-3297.

-5 Ghobrial MW, George J, Mannam S, Henien SR: Severe hypercalcemia as an initial presenting manifestation of hepatocellular carcinoma. Can J Gastroenterol 2002;16:607-609.

-6 Hwang SJ, Luo JC, Li CP, Chu CW, Wu JC, Lai CR, Chiang JH, Chau GY, Lui WY, Lee CC, Chang FY, Lee SD: Thrombocytosis: a paraneoplastic syndrome in patients with hepatocellular carcinoma. World J Gastroenterol 2004;10:24722477.

-7 Hirayama T, Honda A, Matsuzaki Y, Miyazaki T, Ikegami T, Doy M, Xu G, Lea $\mathrm{M}$, Salen G: Hypercholesterolemia in rats with hepatomas: increased oxysterols accelerate efflux but do not inhibit biosynthesis of cholesterol. Hepatology 2006;44:602-611. 